\title{
Switching Angle Estimation using GA Toolbox for Simulation of Cascaded Multilevel Inverter
}

\author{
Kaibalya Prasad Panda \\ M.tech \\ KIIT University \\ Bhubaneswar
}

\author{
Bishnu Prasad Sahu \\ M.tech \\ KIIT University \\ Bhubaneswar
}

\author{
Yatindra Gopal \\ M.tech \\ KIIT University \\ Bhubaneswar
}

\author{
Debashis Samal \\ M.tech \\ KIIT University \\ Bhubaneswar
}

\begin{abstract}
Higher power levels can be obtained from utilizing lower voltage levels which was the theory proposed over thirty years ago. Conversion of DC to AC having desired output voltage and frequency can be obtained from two types of inverters which are single level and multilevel inverter (MLI). Amongst all MLI topologies, Cascaded H-Bridge type is taken into consideration for this paper. Advantages of MLI include minimum harmonic distortion, reduced EMI and it can be operated on different voltage levels. Here IGBT's are taken as switches which are to be controlled by providing proper switching angles that is generated by any optimization techniques. Here genetic algorithm (GA) is taken as the optimization method and switching angles are derived and the sane is compared with conventional Newton-Raphson (NR) method. Simulation of cascaded H-Bridge multilevel inverter of single phase 5-level, 7-level and 11- level cascaded multilevel inverter is presented and the output waveforms were observed using MATLAB.
\end{abstract}

\section{Keywords}

MLI, Genetic Algorithm, THD and Simulink

\section{INTRODUCTION}

The principle behind the multilevel inverter is to achieve a high power using series connected semiconductor switches i.e. IGBT, MOSFET etc. with the separate dc sources which helps in conversion of power from dc to ac. The output ac is in the form of staircase manner which should be nearer to sinusoidal waveform $[1,2]$ and to obtain this, proper switching angles should be generated using optimizing techniques to control switching frequencies of each semiconductor switches connected. The primary structure of MLI have been designed to obtain high power range utilizing multiple dc voltage levels, so that it can be useful for high operating voltage electrical systems. Use of transformer is not needed, which can put a pause to design of MLI because of its cost-maintenance and low distortion i.e. output containing low harmonics can be obtained. Hence the topology is most suitable for FACTS devices and many high power application systems $[3,4]$.
Multilevel inverter are mainly used to obtain ac voltage from several dc voltages, so it can be used in integration with the renewable energy sources like fuel cells, photovoltaic cells etc [5]. A hybrid connection of MLI with the ac grids can be possible because of functional compatibility. MLI's are also best suitable for applications like VAR compensation, selective harmonic filtering, drives application etc. The integration of MLI with renewable energy sources will be advantageous because of its availability, faster response, and self controlling capability. The real and reactive power flow can be controlled from the renewable energy sources which are a very attractive feature for low power quality problems.

MLIs are mainly classified into three types i.e. (a) Cascaded $\mathrm{H}$-Bridge type which can be series or parallel connected and more advantageous to use than other topologies. (b) Diode clamped type which provides different voltage levels by connecting series bank capacitors and the number of levels that are being limited to three levels because of the voltage balancing issues. The main disadvantage of using this topology is the use of more number of diodes. (c) Flying capacitor type which is designed by series connection of capacitor clamped switching cells and disadvantageous to use because of the more number of use of capacitors.

Many hybrid structures are also emerged in recent years which are more advantageous than the elementary topologies [6]. The topology cascaded H-bridge multilevel inverter is advantageous with respect to other topologies as voltage level can be easily increased in steps by increasing the number of dc sources. An apparent disadvantage of this topology is that large numbers of switches are required.

Multilevel inverter helps in synthesizing desired staircase output voltage waveform from several dc sources used as input for the multilevel inverter [7]. Increase in the number of dc source leads closer to the pure sinusoidal voltage waveform. These multilevel inverters found there applications in induction motor drives, static VAR compensation, UPS system, laminators, mills, conveyors and compressors etc. To obtain the sinusoidal voltage waveform from multiple $\mathrm{dc}$ sources the semiconductors switches are switched on and off in such a way to keep the total harmonic distortion (THD) \% 
to its minimum value. Switching angles are calculated by the help of optimization technique. The harmonics equation obtained is nonlinear in nature and thus optimization methods are available to solve the harmonics equation to eliminate the particular harmonics. The available methods to solve these transcendental equations include Nelder Mead method, genetic algorithm, Newton Raphson method etc [8]. Using this iterative methods THD (\%) and switching angles are calculated which is then applied to the pulse generators of IGBTs, so as to get lesser THD. In this paper GA (genetic algorithm) toolbox is used as the optimization method because of its faster response and is also a less time consuming approach. The results are being compared with the conventional Newton-Raphson method.

\section{FEATURES OF MULTILEVEL INVERTER}

- Ability to reduce the voltage stress on each power device due to the utilization of multiple levels on the DC bus.

- Important when a high DC side voltage is imposed by an application (e.g. traction systems).

- Even at low switching frequencies, smaller distortion in the multilevel inverter AC side waveform can be achieved (with stepped modulation technique).

- Multilevel inverters produce smaller common mode (CM) voltage; therefore, the stress in the bearings of a motor connected to a multilevel motor drive can be reduced. Furthermore, CM voltage can be eliminated by using advanced modulation strategies [9].

- When levels are increased the switching losses are decreased whereas the conduction losses are constant which is mainly applicable in flying capacitor topology [10].

\section{CASCADED MULTILEVEL INVERTER TOPOLOGY}

Cascaded single-phase H-bridge gets supply from separate dc sources (SDCSs). As indicated in the introduction part the need of renewable energy sources such as fuel cells or photovoltaics are the obvious choice for the isolated dc voltage sources needed for the cascade inverter. Fig. 1 shows a single-phase 7-level cascade inverter. Each SDCS is connected to a single-phase full-bridge, or H-bridge, inverter which is connected in a series fashion.

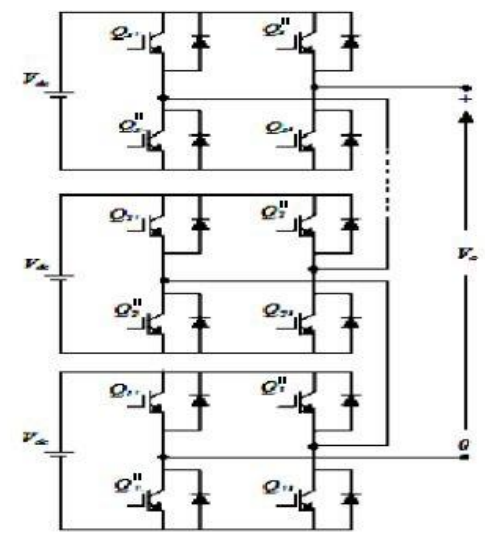

Fig 1: Cascaded Multilevel Inverter topology

Each level of inverter can generate three different voltage outputs, $+\mathrm{V}_{\mathrm{dc}}, 0$, and $-\mathrm{V}_{\mathrm{dc}}$ by different combinations of the four switches, $\mathrm{Q}_{1}, \mathrm{Q}_{2}, \mathrm{Q}_{1}$, , and $\mathrm{Q}_{2}$ " as shown in Table.1. The ac outputs of each of the different full-bridge inverter levels are connected in series such that the synthesized voltage waveform is the sum of the inverter outputs. The number of output phase voltage levels ' $m$ ' in a cascade inverter is defined by $\mathrm{m}=2 \mathrm{~s}+1$, where ' $\mathrm{s}$ ' is the number of separate dc sources (photovoltaic modules or fuel cells). An example of phase voltage waveform for a 7level cascaded H-bridge inverter with 3 SDCSs and 3 full bridges is shown in Fig. 2. The phase voltage $v_{\mathrm{an}}=\mathrm{v}_{\mathrm{a} 1}+\mathrm{v}_{\mathrm{a} 2}+$ $v_{\mathrm{a} 3}$. The conducting angles, $\theta_{1}, \theta_{2}, \ldots, \theta_{\mathrm{s}}$, can be chosen such that the total harmonic distortion is a minimum.

Table 1. Switching sequence of MLI

\begin{tabular}{|c|c|c|}
\hline $\begin{array}{c}\text { SL } \\
\text { NO. }\end{array}$ & SWITCHING SEQUENCE & OUTPUT \\
\hline 1. & Q1 \& Q2 & + +Vdc \\
\hline 2. & Q1" \& Q2" & -Vdc \\
\hline 3. & Q1 \& Q1" or Q2 \& Q2" & 0 \\
\hline
\end{tabular}

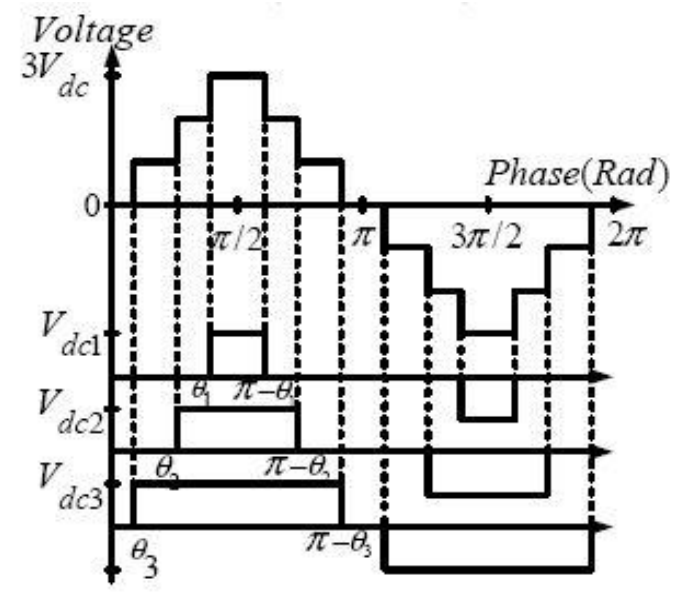

Fig 2: Output waveform of 7 level MLI

\section{CALCULATION OF SWITCHING ANGLES BY GENETIC ALGORITHM TOOLBOX}

Genetic Algorithm (GA) is a method used for solving both constrained and unconstrained optimization problems based on natural selection, the process that drives biological evolution. The GA repeatedly modifies a population of individual solutions. At each step, GA selects the individuals at random from the current population to be parents and uses them to produce the children for the next generation. Over successive generations, the population "evolves" towards an optimal solution [11]. GA uses three main rules at each step to create the next generation from the current population:-

- Selection rules in selecting the individuals, called parents that contribute to the population to the next generation.

- Crossover rules in combining two parents to form children for the next generation.

- Mutation rules apply random changes to individual parents to form children.

\subsection{Algorithm}

- Randomly select some switching angles.

- Calculate generation index and population index.

- If $0<\alpha 1<\alpha 2<\alpha 3<\pi / 2$ else goto next step. 
- Computation of objective function $\mathrm{F}(\alpha)$.

- Pick the best individuals.

- Create new set of values using crossover and mutation process.

- The switching angles are obtained after converging otherwise repeat for next generation [12].

To use GA toolbox (where GA algorithm is inbuilt in MATLAB) shown in Fig $3 \&$ following information should be entered:-

- Create a function which is to be minimized (THD) called the fitness function.

- Enter the number of variables used.

- Clicking the START button we can compute the iterated values.

- Using plot function we can plot the individuals and best fitness shown in Fig 4.

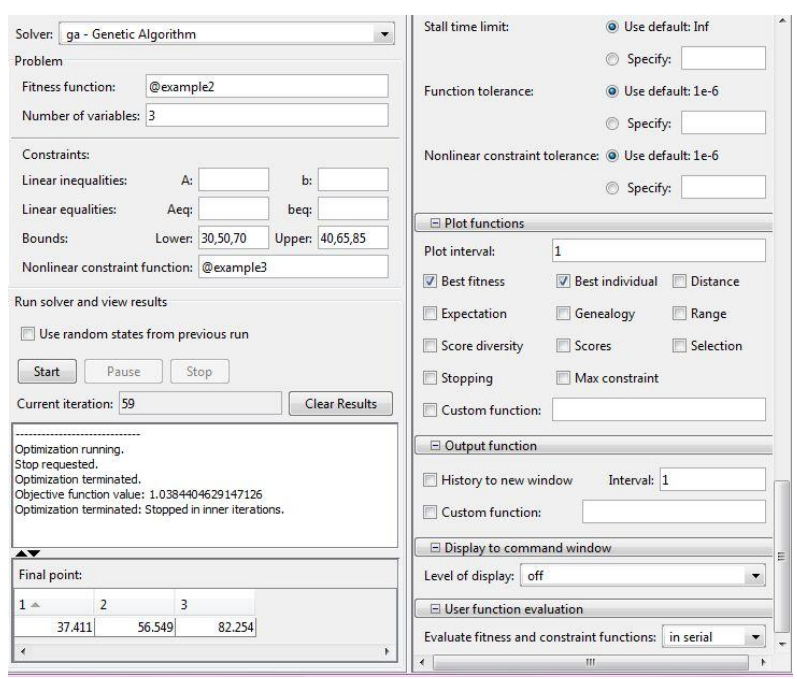

Fig 3: Use of Genetic Algorithm toolbox

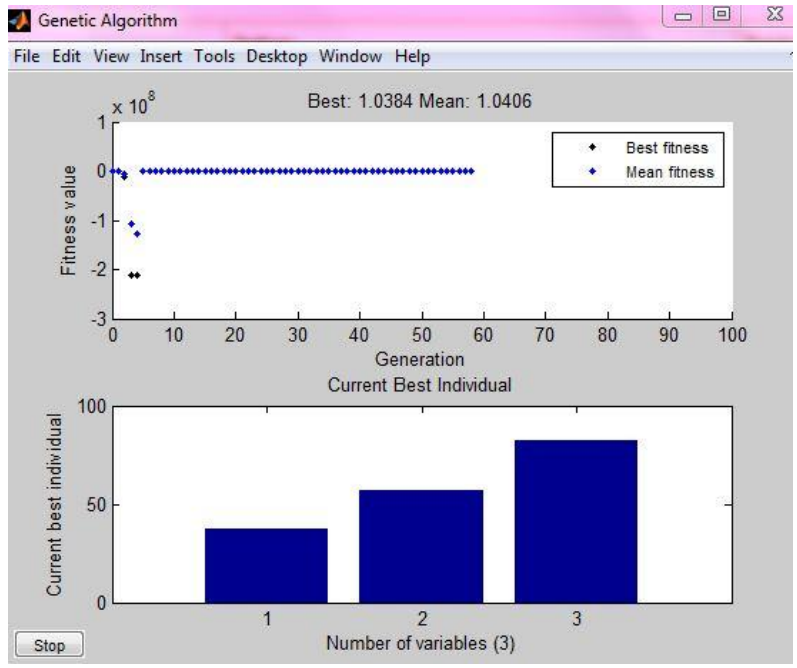

Fig 4: Results obtained from Genetic Algorithm

\section{SIMULATION STUDY OF MLI}

Simulation of 1 phase 5-level, 7-level and 11-level cascaded multilevel inverter is done using simulink from MATLAB. IGBTs are chosen as switching device for simulation, since it has more features than the other power semiconductor devices.

\subsection{Simulation of 5 level MLI}

For simulation of a 5-level MLI two dc sources are used as shown in Fig 5. In this paper two 100V dc sources are selected. It can be done with unequal dc sources also. For the $1^{\text {st }}$ level of output IGBT1 and IGBT2 are in operation in the positive half cycle. In this simulation 0.02 is taken as one period and phase delay is taken as 0.002 (switching angle 1) for both IGBT's. Then for $2^{\text {nd }}$ level IGBT $5 \& 6$ are in operation and phase delay is taken as 0.004 (switching angle 2). Similarly for the negative half cycle for the $1^{\text {st }}$ level of output IGBT $3 \& 4$ are in operation and for $2^{\text {nd }}$ level IGBT $7 \& 8$ are in operation. Connect a powergui block and set it to discrete mode. From the powergui block FFT analysis is done, so that THD can be calculated as shown in Fig.7.

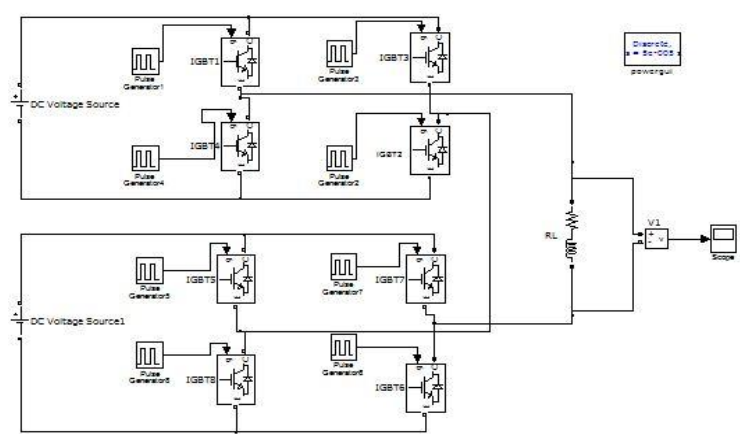

Fig 5: Simulation of 5 level MLI

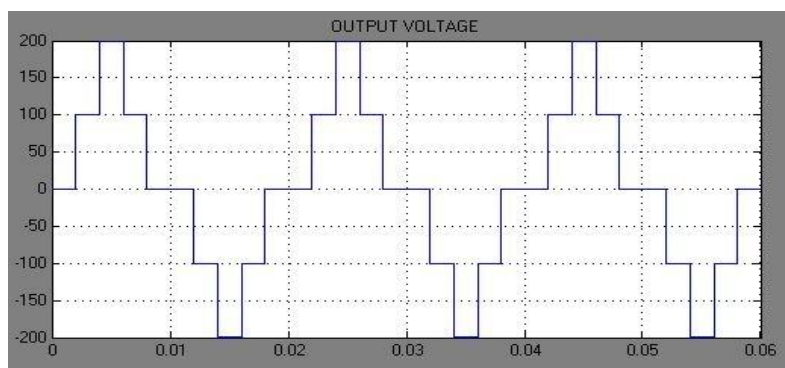

Fig 6: Output of 5 level MLI

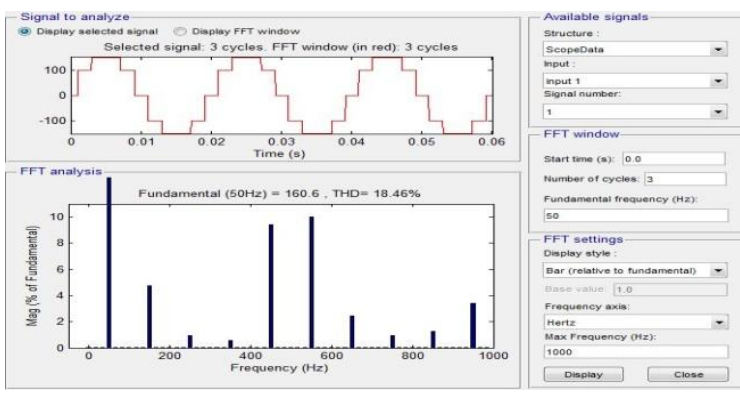

Fig 7: FFT analysis of 5 level MLI

As the inverter levels are increased the THD decreases, because the output will be nearer to sinusoidal. So as to prove this simulation of 7-level is shown in Fig 8. 


\subsection{Simulation of 7 level MLI}

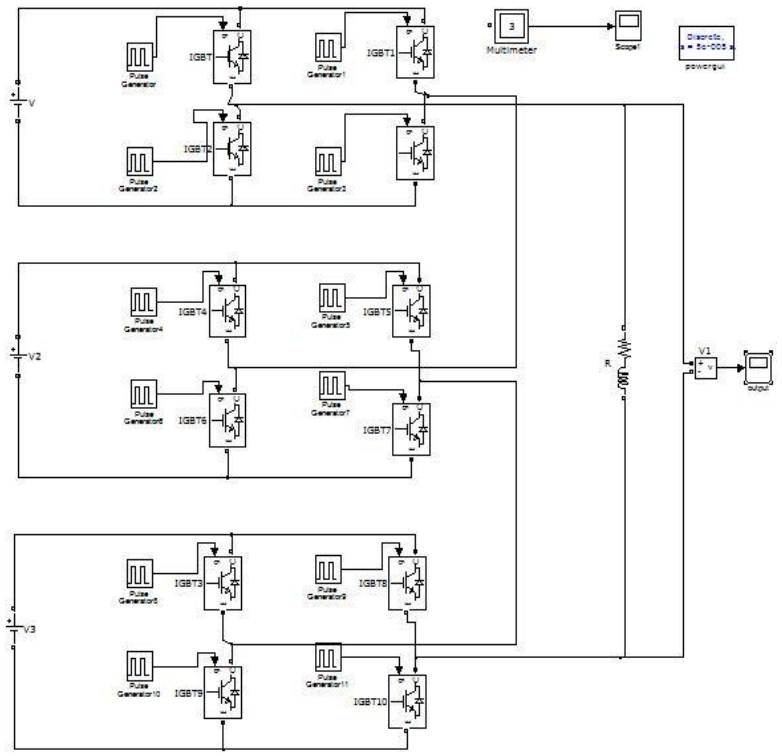

Fig 8: Simulation of 7 level MLI

A 7-level MLI, operation is similar as 5-level. Diagonally IGBTs are in operation in each level for positive and negative half cycle and the output waveform is shown in Fig 9. Here phase delays for 3 levels are taken as $0.002,0.003$ and 0.004 which are three switching angles calculated from GA toolbox.

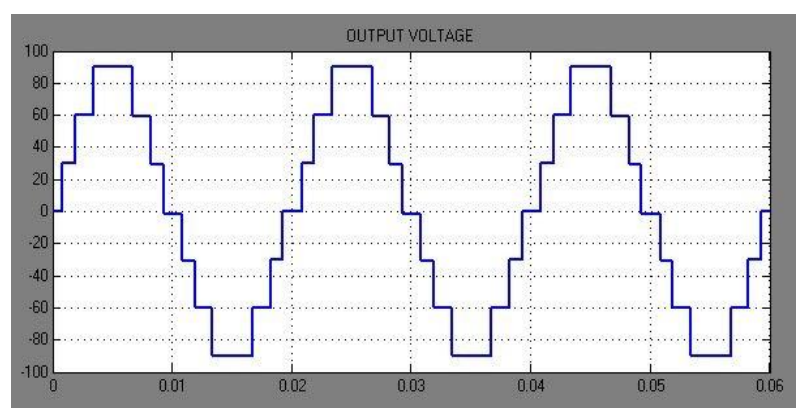

Fig 9: Output of 7 level MLI

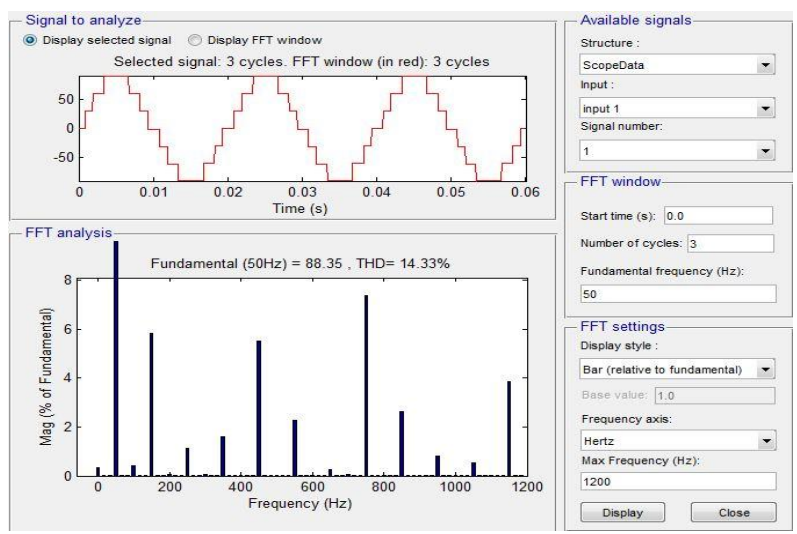

Fig 10: FFT analysis of 7 level MLI 11-level MLI operation is also similar as 5-level. Diagonally IGBTs are in operation in each level for positive and negative half cycle. Here phase delays for 5 levels are taken as $0.0008,0.0018,0.0028,0.0038$ and 0.0048 which are five switching angles calculated from GA toolbox. The output waveform of 11 level MLI is shown in Fig 11 which verifies that when the level increases THD (\%) decreases.

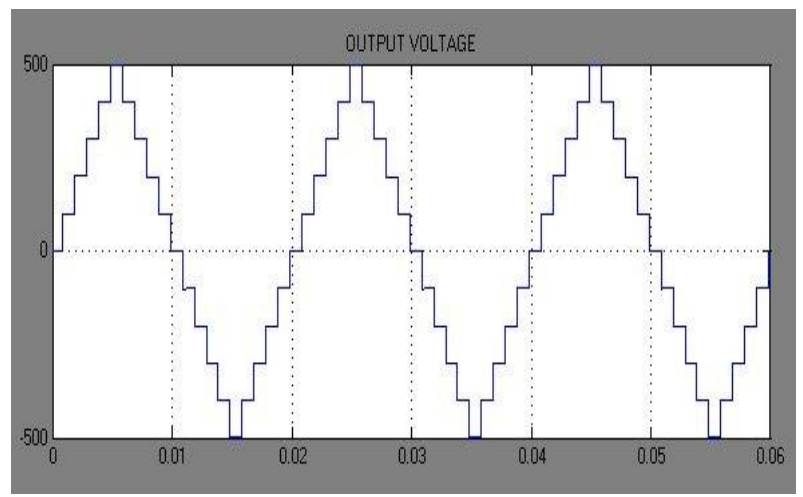

Fig 11: Output of 11 level MLI

\section{RESULT COMPARISON OF GA AND NR METHOD}

\subsection{Results obtained from GA}

Table 2. Switching Angles Vs THD for 5 level MLI

\begin{tabular}{|c|c|c|c|}
\hline MI & $\alpha 1$ & $\alpha 2$ & THD (\%) \\
\hline 0.1 & 37.8 & 87.91 & 21.13 \\
\hline 0.3 & 43.2 & 86.4 & 19.113 \\
\hline 0.5 & 41.93 & 88.878 & 19.03 \\
\hline 0.9 & 28.94 & 76.45 & 13.71 \\
\hline
\end{tabular}

Table 3. Switching Angles Vs THD for 7 level MLI

\begin{tabular}{|c|c|c|c|c|}
\hline MI & $\alpha 1$ & $\alpha 2$ & $\alpha 3$ & THD (\%) \\
\hline 0.1 & 9.998 & 12.5412 & 24.831 & 18.412 \\
\hline 0.2 & 7.318 & 19.1583 & 37.617 & 14.6786 \\
\hline 0.5 & 25.954 & 44.658 & 56.554 & 11.151 \\
\hline 0.9 & 37.8302 & 54.4913 & 62.5211 & 9.9413 \\
\hline
\end{tabular}




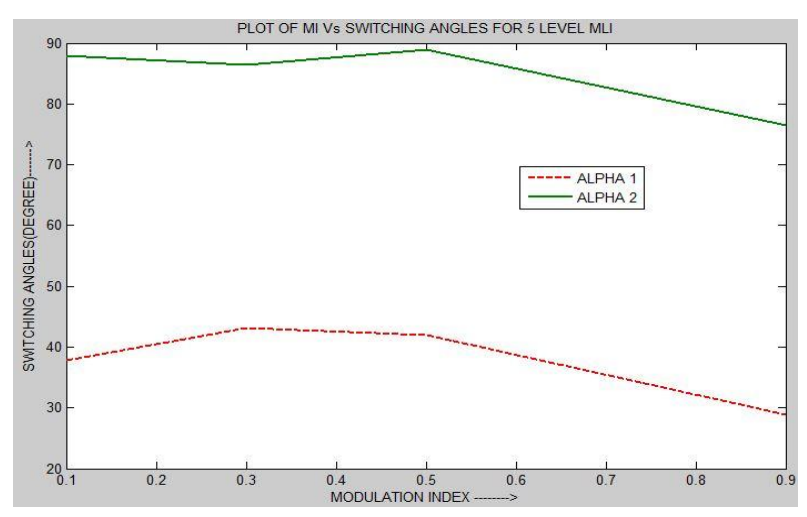

Fig 12: Modulation index Vs switching angle plot

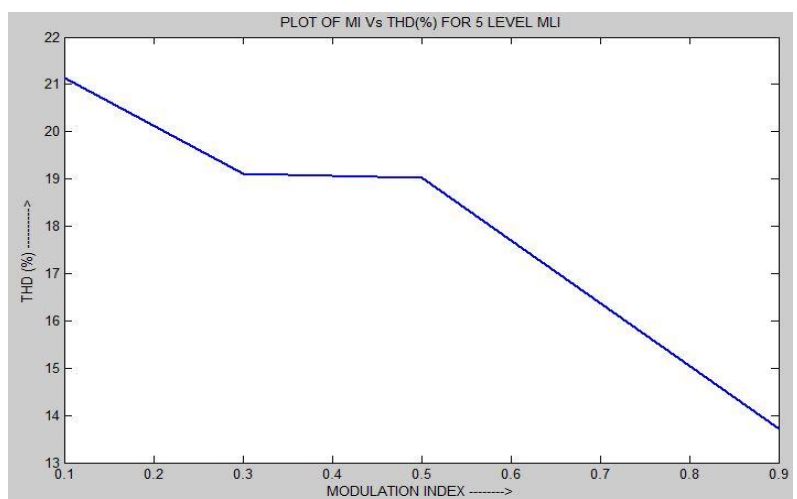

Fig 13: Modulation index Vs THD (\%) plot

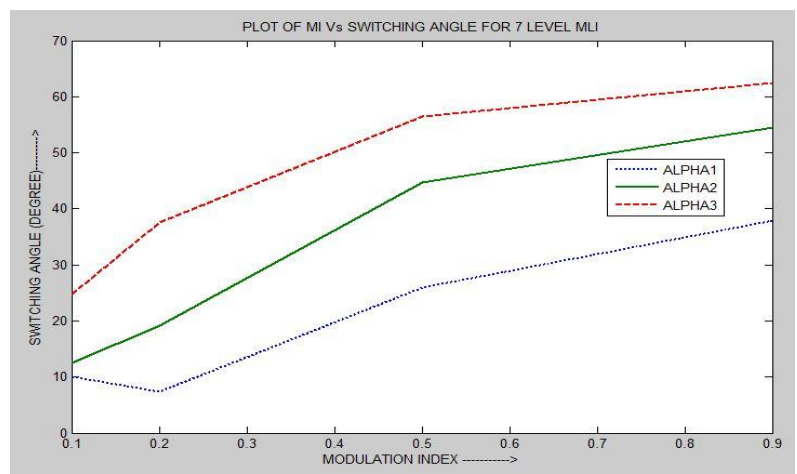

Fig 14: Modulation index Vs switching angle plot

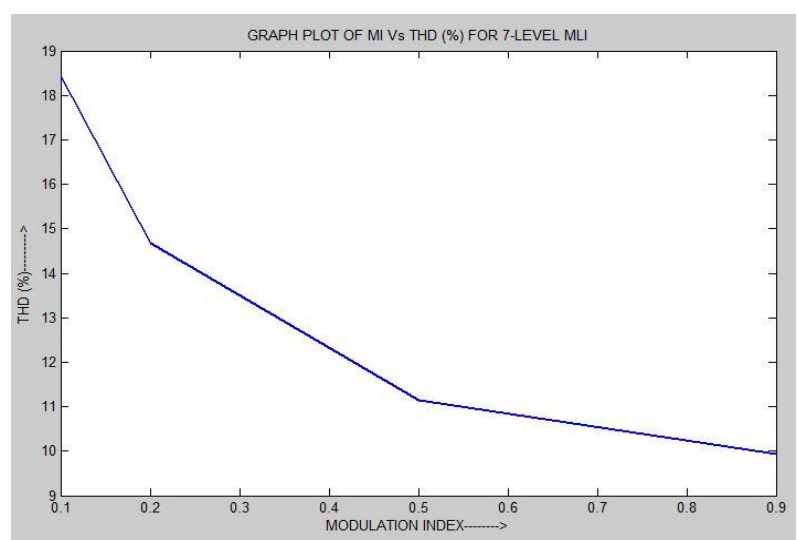

Fig 15: Modulation index Vs THD (\%) plot

\subsection{Results obtained from NR}

Table 4. Switching Angles Vs THD for 5 level MLI

\begin{tabular}{|c|c|c|c|}
\hline MI & $\alpha 1$ & $\alpha 2$ & THD (\%) \\
\hline 0.5 & 10.87 & 50.83 & 30.1977 \\
\hline 0.7 & 11.24 & 32.49 & 21.1378 \\
\hline 0.9 & 10.92 & 76.22 & 15.145 \\
\hline 1 & 36.27 & 87.44 & 14.82 \\
\hline
\end{tabular}

Table 5. Switching Angles Vs THD for 7 level MLI

\begin{tabular}{|c|c|c|c|c|}
\hline MI & $\alpha 1$ & $\alpha 2$ & $\alpha 3$ & THD (\%) \\
\hline 0.1 & 11.1917 & 33.3512 & 53.048 & 17.532 \\
\hline 0.2 & 15.7781 & 48.142 & 73.377 & 16.2105 \\
\hline 0.5 & 34.2113 & 77.701 & 88.6321 & 12.3591 \\
\hline 0.9 & 26.425 & 70.721 & 86.198 & 12.1418 \\
\hline
\end{tabular}

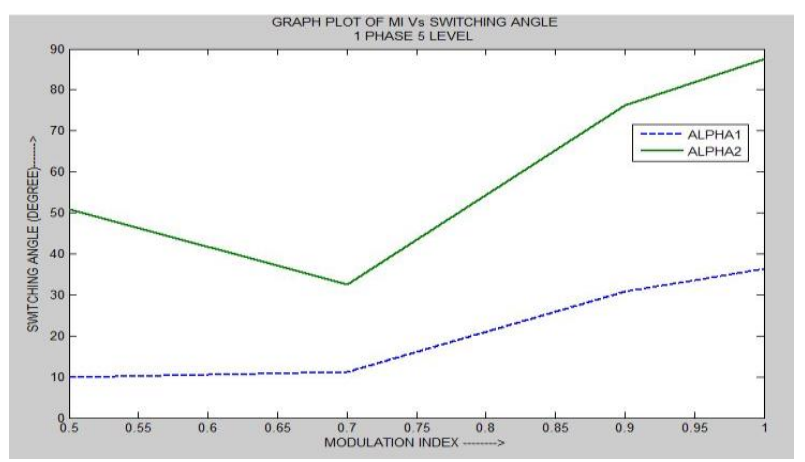

Fig 16: Modulation index Vs switching angle plot

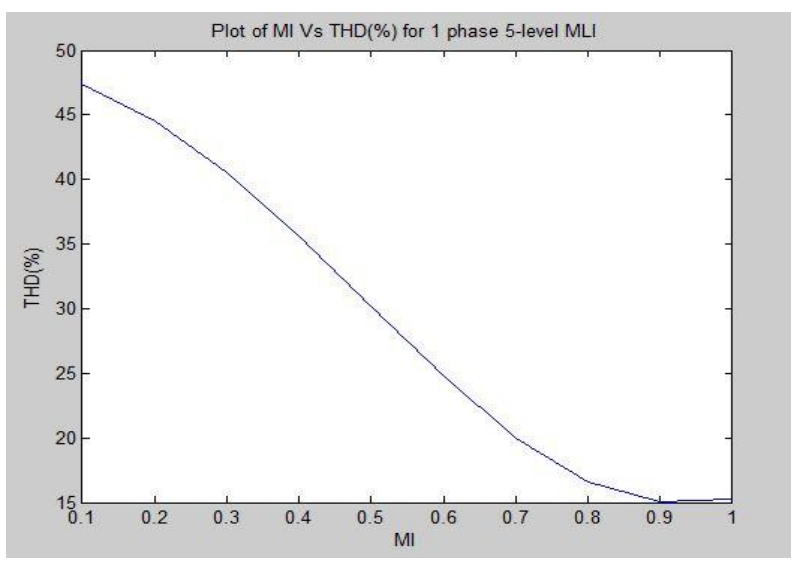

Fig 17: Modulation index Vs THD (\%) plot 


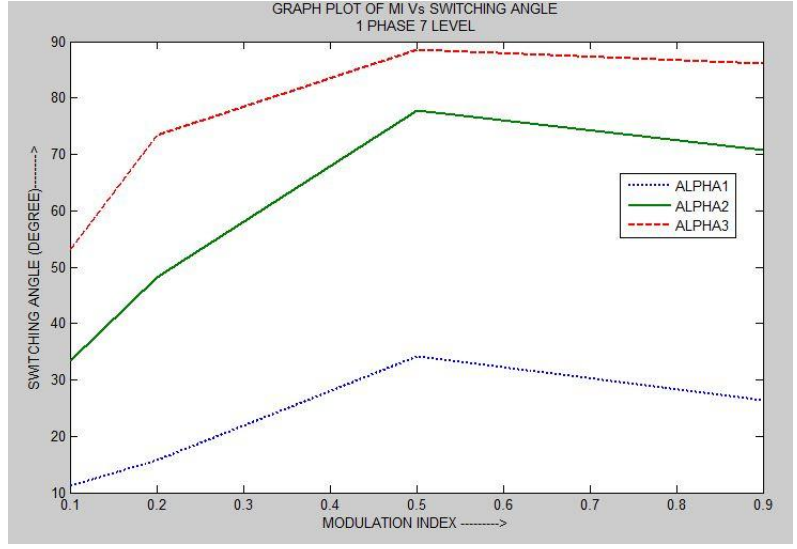

Fig 18: Modulation index Vs switching angle plot

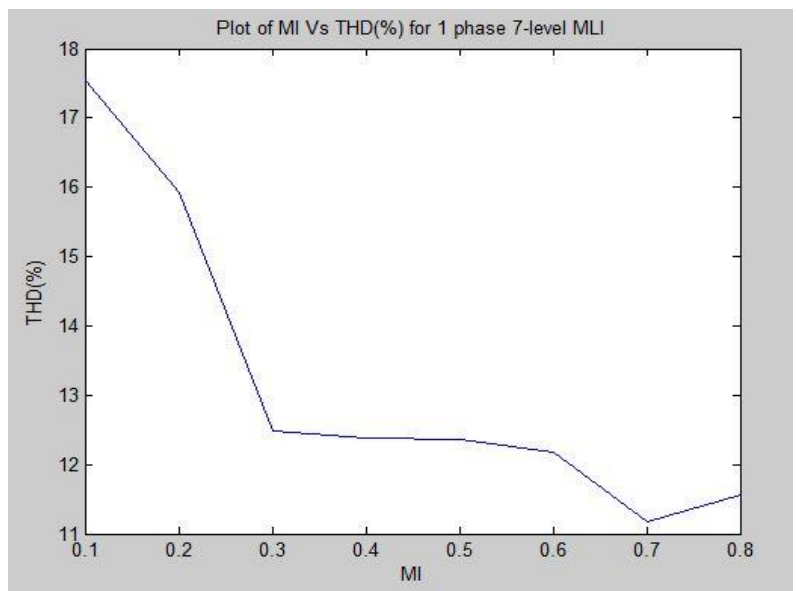

Fig 19: Modulation index Vs THD (\%) plot

\section{CONCLUSION}

This work proposed is the simulation of cascaded multilevel inverter of different levels. Genetic algorithm is used because it's the time consuming process and most importantly in-built in MATLAB and the results are compared with the conventional Newton Raphson method. From the different levels of simulation it is clear that THD can be decreased by increasing number of levels. Purpose of this work is that just to know the simulation process and the optimization method which is helpful in selective harmonic elimination. By using 5-level $5^{\text {th }}$ harmonics can be eliminated likewise in 7-level $5^{\text {th }}$ and $7^{\text {th }}$ harmonics can be eliminated $\&$ in 11 -level $5^{\text {th }}, 7^{\text {th }}$ and $11^{\text {th }}$ order harmonics can be eliminated. The multilevel inverter improves output voltage; reduce THD and voltage stresses on semiconductor switches which can be verified from simulation results.

\section{REFERENCES}

[1] Leon M. Tolbert and Fang Z peng, "Multilevel inverter as a utility interface for renewable energy systems," in Proceedings of 2000 IEEE Power Engineering Society Summer Meeting, pp. 1271-1274.

[2] L. M. Tolbert, F. Z. Peng, and T. Habetler, "Multilevel Converters for Large Electric drives," IEEE Transactions on Industry Applications, vol. 35, Jan./Feb. 1999, pp. 36-44.

[3] L. Gyugi, "Dynamic Compensation of AC Transmission Lines by Solid-State Synchronous Voltage Sources," IEEE Transactions on Power Delivery, vol.9, no. 2, April 1994, pp. 904-911

[4] A van Zyl, J.H.R. Enslin, R. Spee, " A new unified approach to power quality management, " IEEE Transactions on Power Electronics, vol. 11, no. 5, Sept.1996, pp. 691-697

[5] R. Hill, "Grid connected solar PV," IEE Colloquium on Developments in Photovoltaic Electricity Production, March 1997

[6] J. S. Lai and F. Z. Peng, "Multilevel Converters-A new Breed of Power Converters," IEEE Trans. Ind. Applicat., vol.32,pp. 509-517, May/June 1996.

[7] F. Z. Peng, J. W. McKeever, D.J Adams, "Cascade Multilevel Inverters for Utility Applicatios, " Proc. Of the Industrial Electronics, Control and Instrumentation Conference (IECON), 1997, pp. 437-442

[8] Leon M. Tolbert, John N. Chiasson, Zhong Du, Keith J. McKenzie:" Elimination of Harmonics in a Multilevel Converter". IEEE Transactions on Application Industry, Vol.41, No.1, January/februry 2005.

[9] E. Cengelci, S. U. Sulistijo, B. O. Woom, P. Enjeti, R. Teodorescu, and F. Blaabjerg, "A New Medium Voltage PWM Inverter Topology for Adjustable Speed Drives," in Conf. Rec. IEEE-IAS Annu. Meeting, St.Louis, MO, Oct. 1998, pp. 1416-1423.

[10] L. M. Tolbert, F. Z. Peng, T. G. Habetler, "Multilevel Inverters for Electric Vehicle Applications," IEEE Workshop on Power Electronics in Transportation, Oct 22-23, 1998, Dearborn, Michigan, pp. 1424-1431.

[11] Debnath, S.; Ray, R.N., "Harmonic Elimination in Multilevel Inverter using GA," 2012 IEEE Students' Conference on Electrical, Electronics and Computer Science, pp 1-5

[12] Sabahi, M.; Iranaq, A.R.M.; Bahrami, K.M.; Bahrami, K.M.; Sharifian, M.B.B., "Harmonics Elimination in a Multilevel Inverter with Unequal DC Sources Using Genetic Algorithm" IEEE Trans. Ind. Electron., pp. 1-5, February 2011. 